\title{
Antibiotic Susceptibility Pattern of Bacterial Isolates from Soft Tissues Infection among Patients Visiting Birendra Military Hospital, Chhauni, Kathmandu
}

\author{
Kushaalta Giri ${ }^{1}$, Sharada Gurung ${ }^{1}$, Simrika Subedi ${ }^{1}$, Alina Singh ${ }^{3}$ and Nabaraj Adhikari ${ }^{2 *}$ \\ ${ }^{1}$ Department of Microbiology, Sainik Awasiya Mahavidyalaya, Sallaghari, Bhaktapur \\ ${ }^{2}$ Central Department of Microbiology, Tribhuvan University, Kirtipur \\ ${ }^{3}$ Birendra Military Hospital, Chhauni, Kathmandu
}

*Corresponding author: Nabaraj Adhikari, Central Department of Microbiology, Tribhuvan University: E-mail: adhikarinaba13@gmail.com

\section{ABSTRACT}

Objectives: To determine the rate of soft tissues infection and perform antibiotic pattern susceptibility test of bacterial pathogens isolated from soft tissue infected patients visiting Shree Birendra Hospital, Kathmandu, Nepal.

Methods: A total of 380 wound specimens (open and closed) including pus and wound swabs were processed in the laboratory of Birendra Military Hospital, Chhauni from August to November 2018. The specimens were cultured on Blood Agar blood agar and Mac-Conkey agar and incubated at $37^{\circ} \mathrm{C}$ for $24 \mathrm{hrs}$. Antibiotic Susceptibility Test was performed by using modified Kirby-Bauer disc diffusion method. Thus, multidrug resistant (MDR) bacteria and methicillin resistant Staphylococcus aureus (MRSA) were differentiated.

Results: Out of 380 bacterial isolates, 86(43.21\%) were Gram positive and 113(56.78\%) were Gram negative bacteria. Among all the Gram-positive isolates 43(53.09\%) were found to be MRSA. Similarly, 62(54.86\%) were found to be MDR among the Gram-negative bacteria. Gentamicin and Amikacin were found to be the most effective drug though the resistance pattern is not homogenous against all isolates.

Conclusion: Antibiotic susceptibility pattern of all bacterial isolates showed that, Gentamycin, Amikacin, Levofloxacin, Piperacillin/ Tazobactam, Doxycycline were the effective drug for Gramnegative bacteria and Amikacin, Teicoplanin, Linezolid, Doxycycline, Gentamycin and Azithromycin were the most effective drug for Gram-positive organisms. Thus it can be concluded that these antibiotics may be used for the empirical treatment of soft tissues infection.

Key words: Antibiotic susceptibility, bacteria, soft tissue, MRSA

\section{INTRODUCTION}

Soft tissues infections are infection of the skin and soft tissue and are usually caused by bacteria. The infection develops when there is a break in the skin, such as a wound or athlete's foot, which may be minor or even unnoticed. This allows bacteria to enter through the skin and grow, causing infection and swelling. People suffering from cut, scarps or other abrasion can get any of this infection. The symptoms of skin and soft tissue infections are all very similar and usually include swelling and redness of the skin as well as warmth radiating from the area. Other symptoms include

Date of Submission: October 7, 2019

Published Online: December, 2019 smooth and shiny skin, small blisters and pimples that get formed in the area (Baddour 2019).

The most common pathogens in these infections are Staphylococcus aureus (including MRSA), P. aeruginosa, Enterococcus spp, Escherichia coli and other antibiotics resistant Enterobacteriaceae (Rosser et al. 2005).

The performance of antimicrobial susceptibility testing by the clinical microbiology laboratory is important to confirm susceptibility to chosen empirical antimicrobial agents or to detect resistance in individual bacterial isolates (Edelsberg et al. 2009). Multidrug resistant

Date of Acceptance: November 24, 2019

DOI: https:/ / doi.org/10.3126/tujm.v6i0.26595 
bacteria, bacteria that resist to more than three classes of antibiotics, are more problematic as compared to normal bacteria because infections with multidrugresistant bacteria are hard to treat since few or even no treatment options remain (Magiorakos et al. 2012). In some cases, health care providers have to use antibiotics that are more toxic for the patient. Multidrug-resistance facilitates spread of antibiotic resistance. When multidrug-resistance plasmids are transferred to other bacteria, these become resistant to many antibiotics at once. In environments where bacteria are continuously exposed to antibiotics, like in hospitals or some large production animal farms, multidrug-resistance may be favorable and are therefore selected and spread further (Bessa et al. 2013). Multidrug-resistance complicates efforts to reduce resistance. When many different antibiotics are selected for the same resistant bacteria or plasmids, reducing use of one type of antibiotic is not enough to reduce resistance to that antibiotic. Thus, there is an increasing prevalence of pathogenic multidrug-resistant bacteria globally. An example is ESBL (extended spectrum beta lactamase)-producing Gram-negative bacteria like E. coli and Klebsiella pneumoniae (Woerther et al. 2013).

Methicillin resistant Staphylococcus aureus (MRSA) emerged as a cause of infection among patients exposed to the bacteria in health care centers. It is a common cause of hospital and community acquired infections worldwide (Barret et al. 1968). Treatment of S. aureus infections which has now become more challenging with the emergence of MRSA, are often multidrug resistant (Ciccarone et al. 2001).

\section{MATERIALS AND METHODS}

Study site and population

A hospital based descriptive cross-sectional study was conducted during August- November 2018 at Shree Birendra Hospital Chhauni, Kathmandu, Nepal. A total of 380 specimens (pus and swab) were processed from soft tissues infection during study period. The study populations were the patients irrespective of age and sex with soft tissue infection as referred by the physicians for routine clinical care.

Isolation and identification: Wound Swabs were

Table 1: Growth pattern of the specimen

\begin{tabular}{lcc}
\hline Growth & Number & Percentage \\
\hline Growth & 199 & 52.36 \\
No growth & 181 & 47.63 \\
\hline Total & 380 & 100 \\
\hline
\end{tabular}

collected and inoculated on Blood agar plates and Mac-Conkey agar plates. The blood agar plates were incubated at $37^{\circ} \mathrm{C}$ for $24 \mathrm{hrs}$ enriched with $\mathrm{CO}_{2}$ while Mac-Conkey agar plates were aerobically incubated in ordinary incubation at $37^{\circ} \mathrm{C}$ for $24 \mathrm{hrs}$. Blood agar was examined for haemolysis of the medium, colonial characteristic and gram staining was carried out. MacConkey agar plates were examined for Gram's negative organism and lactose fermenter and non-lactose fermenter and colonial character of the organism (WHO 2003).

Isolates were identified using standard microbiological techniques as described by Cheesbrough (2006), comprising of colony morphology, Gram staining and various other biochemical tests such as catalase production test, coagulase production test, oxidase test, IMViC tests, Triple sugar iron agar tests, etc. and reported accordingly.

Antibiotic susceptibility testing: The antibiotic susceptibility testing of individual isolate was carried out by modified Kirby-Bauer disc diffusion method as per CLSI guidelines (2014) using Muller Hinton Agar (MHA). In this study antibiotics used were Ampicillin $(10 \mu \mathrm{g})$, Ceftriaxone $(30 \mu \mathrm{g})$, Ciprofloxacin $(5 \mu \mathrm{g})$, Cloxacillin $(5 \mu \mathrm{g})$, Cotrimoxazole

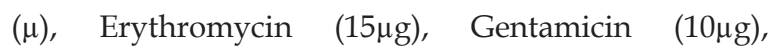

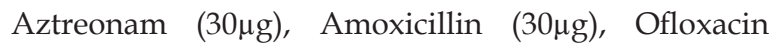
$(5 \mu \mathrm{g})$, Cefepime $(30 \mu \mathrm{g})$, Amikacin $(30 \mu \mathrm{g})$, Amoxyclav $(20 / 10 \mu \mathrm{g}), \quad$ Clindamycin $(2 \mu \mathrm{g}), \quad$ Levofloxacin $(5 \mu \mathrm{g})$, Cefotaxime $(30 \mu \mathrm{g})$, Ceftazidime $(30 \mu \mathrm{g})$, Doxycycline $(30 \mu \mathrm{g})$, Azithromycin $(15 \mu \mathrm{g})$, Piperacillin $(100 \mu \mathrm{g})$,

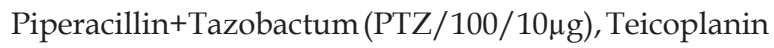
$(30 \mu \mathrm{g})$, Polymyxin B (300unit) and Linezolid $(30 \mu \mathrm{g})$. The organism's showing resistant to more than three different class of antibiotics was taken as Multi-drug resistant isolates (Magiorakos et al. 2012). Screening for methicillin resistance was performed by cefoxitin disc diffusion method and interpreted according to CLSI (2018).

\section{RESULTS}

Out of 380 samples collected, 199 (52.36\%) sample showed growth and 181(47.63\%) showed no growth. (Table 1). 
Out of 380 patients, the rate of infection was found to

females $(16.31 \%)$. (Table 2$)$ be higher among the males $(36.05 \%)$ in comparison to

Table 2: Sex-wise distribution of the patients

\begin{tabular}{lcc}
\hline Sex & Growth (\%) & Total (\%) \\
\hline Male & $137(36.05)$ & $247(65)$ \\
Female & $62(16.31)$ & $133(35)$ \\
\hline Total & $199(52.36)$ & $380(100)$ \\
\hline
\end{tabular}

As far as the age wise distribution is concerned, the

45 to 59 years as shown in table 3 . highest rate of infection was observed in the age group

Table 3: Age-wise distribution of the patients

\begin{tabular}{lcc}
\hline Age (Years) & Growth $\mathbf{n}(\%)$ & Total (\%) \\
\hline$\leq 14$ & $15(3.94)$ & $23(6.05)$ \\
$15-29$ & $42(11.05)$ & $82(21.57)$ \\
$30-44$ & $45(11.84)$ & $94(24.73)$ \\
$45-59$ & $58(15.26)$ & $88(23.16)$ \\
$60-74$ & $31(8.15)$ & $78(20.52)$ \\
$75-89$ & $7(1.84)$ & $14(3.68)$ \\
90 above & $1(0.26)$ & $1(0.26)$ \\
\hline Total & $199(52.36)$ & $380(100)$
\end{tabular}

Out of total 199 bacterial isolates, 113 were Gram negative and 86-Gram positive bacterial isolates. The most predominant isolate was Staphylococcus aureus 81(40.70\%), Escherichia coli accounting for 37 (18.59\%) followed by Pseudomonas spp 30(15.07\%), Klebsiella pneumoniae 18(9.04\%), Acinetobacter spp 13(6.53\%) and

Enterobacter spp 6(3.01\%). The least frequently isolated ones were CoNS 3(1.50\%), Proteus mirabilis 2(1.005\%), Citrobacter freundii 2(1.005\%), Serratia marcescens $2(1.005 \%)$, Citrobacter koserii 2(1.005\%), Klebsiella oxytoca $1(0.50 \%)$, Enterococcus spp $1(0.50 \%)$ and Streptococcus spp $1(0.50 \%)$. (Table 4$)$

Table 4: Distribution patterns of Gram positive and Gram-negative bacteria among growth

\begin{tabular}{lcc}
\hline Organism & Number & Percentage \\
\hline Staphylococcus aureus & 81 & 40.70 \\
Escherichia coli & 37 & 18.59 \\
Pseudomonas aeruginosa & 30 & 15.07 \\
Klebsiella pneumonia & 18 & 9.04 \\
Acinetobacter spp & 13 & 6.53 \\
Enterobacter spp & 6 & 3.01 \\
CoNS & 3 & 1.50 \\
Proteus mirabilis & 2 & 1.01 \\
Citrobacter freundii & 2 & 1.01 \\
Citrobacter koserii & 2 & 1.01 \\
Serratia marcescens & 2 & 1.01 \\
Klebsiella oxytoca & 1 & 0.50 \\
Enterococcus spp & 1 & 0.50 \\
Streptococcus spp & 1 & 0.50 \\
\hline Total & 199 & 100 \\
\hline
\end{tabular}

Among all the antibiotics used, the highest number of $E$. coli $(\mathrm{n}=37)$ were found to be sensitive to gentamicin 29 (78.37\%) followed by doxycycline $18(48.64 \%)$, amikacin 17(45.94\%), levofloxacin 15(40.54\%), Cotrimoxazole 13(35.13\%), Piperacillin+Tazobactum $12(32.43 \%)$ as shown in table 5 .
Out of 19 isolates of Klebsiella spp, 18 isolates were Klebsiella pneumoniae and 1 isolate were Klebsiella oxytoca. Among which the highest number of isolates were most sensitive to doxycycline $9(47.36 \%)$ followed by amikacin $8(42.105 \%)$, and others as shown in table 5 Among 13 isolates of Acinetobacter spp, was subjected 
to AST against 14 antibiotics. Among which the highest isolate was found to be most sensitive to co-trimoxazole $3(23.07 \%)$, levofloxacin $1(7.69 \%)$, gentamicin $1(7.69 \%)$. All the isolates $13(100 \%)$ were resistant to Amoxycilin, Amoxyclav, Ceftriaxone, Cefotaxime, Amikacin,
Ciprofloxacin, Ofloxacin, Piperacillin and PTZ.

Six isolates of Enterobacter spp, was subjected to AST against 14 antibiotics among which the isolate was found to be most sensitive to levofloxacin 5(83.33\%), gentamicin 5(83.33\%) and ofloxacin 4(66.66\%).

Table 5: Antibiotic susceptibility pattern of E. coli, Klebsiella spp, Acinetobacter spp and Enterobacter spp.

\begin{tabular}{|c|c|c|c|c|c|c|c|c|}
\hline \multirow{2}{*}{$\begin{array}{l}\text { Isolates } \\
\text { Antibiotics }\end{array}$} & \multicolumn{2}{|c|}{$\begin{array}{l}\text { E. coli } \\
(\mathrm{n}=37)\end{array}$} & \multicolumn{2}{|c|}{$\begin{array}{c}\text { Klebsiella spp } \\
(n=19)\end{array}$} & \multicolumn{2}{|c|}{$\begin{array}{c}\text { Acinetobacter spp } \\
(n=13)\end{array}$} & \multicolumn{2}{|c|}{ Enterobacter spp $(n=6)$} \\
\hline & $\begin{array}{c}\text { Sensitive } \\
\mathrm{N}(\%)\end{array}$ & $\begin{array}{c}\text { Resistant } \\
\text { N (\%) }\end{array}$ & $\begin{array}{c}\text { S ensitive } \\
\mathrm{N}(\%)\end{array}$ & $\begin{array}{c}\text { Resistant } \\
\text { N (\%) }\end{array}$ & $\begin{array}{c}\text { Sensitive } \\
\mathrm{N}(\%)\end{array}$ & $\begin{array}{c}\text { Resistant } \\
\text { N (\%) }\end{array}$ & $\begin{array}{c}\text { Sensitive } \\
\mathrm{N}(\%)\end{array}$ & $\begin{array}{c}\text { Resistant } \\
\text { N (\%) }\end{array}$ \\
\hline Amoxycilin & $3(8.10)$ & $34(91.89)$ & $0(0)$ & $19(100)$ & $0(0)$ & $13(100)$ & $0(0)$ & $6(100)$ \\
\hline Amoxyclav & $8(21.62)$ & $29(78.37)$ & $1(5.26)$ & $18(94.73)$ & $0(0)$ & $13(100)$ & $0(0)$ & $6(100)$ \\
\hline Ceftriaxone & $6(16.21)$ & $31(83.78)$ & $4(21.05)$ & $15(78.94)$ & $0(0)$ & $13(100)$ & $2(33.33)$ & $4(66.66)$ \\
\hline Cefotaxime & $5(13.51)$ & $32(86.48)$ & $3(15.78)$ & $16(84.21)$ & $0(0)$ & $13(100)$ & $1(16.66)$ & $5(83.33)$ \\
\hline Cotrimoxazole & $13(35.13)$ & $24(64.86)$ & $4(21.05)$ & $15(78.94)$ & $3(23.07)$ & $10(76.92)$ & $3(50)$ & $3(50)$ \\
\hline Gentamycin & $29(78.37)$ & $8(21.62)$ & $6(31.57)$ & $13(68.42)$ & $1(7.69)$ & $12(92.30)$ & $5(83.33)$ & $1(16.66)$ \\
\hline Amikacin & 17(45.94) & $20(54.05)$ & $8(42.11)$ & $11(57.89)$ & $0(0)$ & $13(100)$ & $2(33.33)$ & $4(66.66)$ \\
\hline Ciprofloxacin & $7(18.91)$ & $30(81.08)$ & $4(21.05)$ & $15(78.94)$ & $0(0)$ & $13(100)$ & $1(16.66)$ & $5(83.33)$ \\
\hline Ofloxacin & $9(24.32)$ & $28(75.67)$ & $7(36.84)$ & $12(63.15)$ & $0(0)$ & $13(100)$ & $4(66.66)$ & $2(33.33)$ \\
\hline Levofloxacin & $15(40.54)$ & $22(59.45)$ & $7(36.84)$ & $12(63.15)$ & $1(7.69)$ & $12(92.30)$ & $5(83.33)$ & $1(16.66)$ \\
\hline Piperacillin & $4(10.81)$ & $33(89.18)$ & $0(0)$ & 19(100) & $0(0)$ & $13(100)$ & $1(16.66)$ & $5(83.33)$ \\
\hline PTZ & $12(32.43)$ & $25(67.56)$ & $3(15.78)$ & $16(84.21)$ & $0(0)$ & $13(100)$ & $3(50)$ & $3(50)$ \\
\hline Ampicilin & $7(18.91)$ & $30(81.08)$ & $0(0)$ & 19(100) & $0(0)$ & $13(100)$ & $0(0)$ & $6(100)$ \\
\hline Doxycycline & $18(48.64)$ & $19(51.35)$ & $9(47.36)$ & $12(63.15)$ & $0(0)$ & $13(100)$ & $0(0)$ & $6(100)$ \\
\hline
\end{tabular}

Among 2 isolates of Proteus mirabilis, was subjected to AST against 14 antibiotics among which all isolates were found to be resistant to Amoxycilin 2(100\%) and Cefotaxime 2(100\%). Among four isolates of Citrobacter spp, two isolates were Citrobacter freundii and two were Citrobacter freundii. These bacterial isolates were subjected to AST against 14 antibiotics among which all isolates $4(100 \%)$ were found to be resistant to Amoxycilin, Amoxyclav, Ceftriaxone, Piperacilin, and Cefotaxime. Among 2 isolates of Serratia marcescens, was subjected to AST against 14 antibiotics among which both 2 isolates was found to be resistant to
Amoxyclav and Doxycycline.

Out of 30 isolates of Pseudomonas spp, all were subjected to AST against 9 antibiotics. Among which the highest number of isolates were most sensitive to Polymyxin B 27(90\%), followed by Gentamicin 24(80\%), Amikacin 22(73.33\%), PTZ 22(73.33\%), Aztreonam 22(73.33\%). The lowest sensitivity was towards Cefepime 12(40\%).

Among 199 positive isolates, 113 were Gram negative organisms. Out of total Gram-negative organism isolates $62(54.86 \%)$ were multi drug resistant (MDR) and $51(45.13 \%)$ were not MDR.

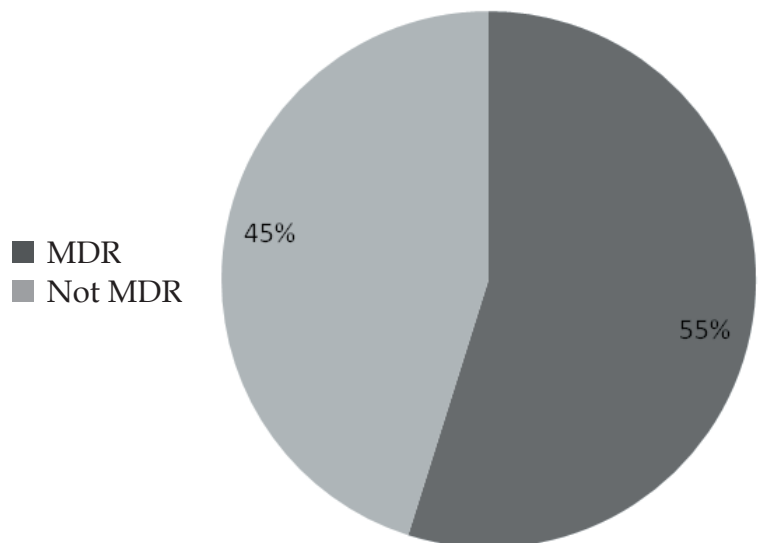

Figure 3: Distribution of MDR among Gram negative isolates 
Altogether 81(94.17\%) Staphylococcus aureus were isolated among 86 Gram positive cocci (GPC)GPC. Among S. aureus, 43 were MRSA and 38 were MSSA. These all S. aureus were subjected towards 12 antibiotics and highest sensitive towards Amikacin was found $79(97.53 \%)$ followed by Teicoplanin $75(92.59 \%)$ and Linezolid $73(90.12 \%)$ and the lowest sensitive to Ampicillin 5(6.17\%).

Three CoNS were isolated among 86 GPC. Only one isolate was Coagulase Negative Staphylococcus aureus but other 2 were Methicillin resistant Coagulase Negative Staphylococcus aureus and subjected towards 12 antibiotics and found highest sensitivity towards Ampicillin 3(100\%) followed by Cotrimoxazole
$3(100 \%)$, Erythromycin 3(100\%), and Azithromycin $3(100 \%)$.

Single Enterococcus spp was found and was subjected AST pattern against 12 antibiotics. It was sensitive against Cotrimozazole, Gentamicin, Amikacin, Ofloxacin, Cloxacillin, Erythromycin, Linezolid and resistant towards others.

Only 2 Streptococcus spp were isolated from 86 GPC isolates and subjected against 12 antibiotics and it was found highest sensitive towards Amikacin 2(100\%), Ofloxacin 2(100\%), Teicoplanin 2(100\%), Linezolid $2(100 \%)$ followed by Gentamycin $1(50 \%)$, Clindamycin 1(50\%), Doxycycline 1(50\%). (Table 6)

Table 6: Antibiotic susceptibility pattern of Gram-positive cocci

\begin{tabular}{|c|c|c|c|c|c|c|c|c|}
\hline \multirow{2}{*}{$\begin{array}{l}\text { Isolates } \\
\text { Antibiotics }\end{array}$} & \multicolumn{2}{|c|}{$\begin{array}{l}\text { Staphylococcus aureus } \\
\qquad(\mathrm{n}=\mathbf{8 1 )}\end{array}$} & \multicolumn{2}{|c|}{$\begin{array}{c}\text { Coagulase Negative } \\
\text { Staphylococcus aureus } \\
(\mathrm{n}=3)\end{array}$} & \multicolumn{2}{|c|}{ Enterococcus spp. $(\mathrm{n}=1)$} & \multicolumn{2}{|c|}{ Streptococcus spp. $(n=2$} \\
\hline & $\mathrm{S} \mathrm{n}(\%)$ & $\mathrm{R} n(\%)$ & $\mathrm{S} \mathrm{n}(\%)$ & $\mathrm{R} \mathrm{n}(\%)$ & $\mathrm{S} \mathrm{n}(\%)$ & $\mathrm{R} n(\%)$ & $\mathrm{S} \mathrm{n}(\%)$ & $\mathrm{R} n(\%)$ \\
\hline Cotrimoxazole & $29(35.80)$ & $52(64.197)$ & $3(100)$ & $0(0)$ & $0(0)$ & $1(100)$ & $2(100)$ & $0(0)$ \\
\hline Gentamicin & $63(77.78)$ & $18(22.22)$ & $1(33.33)$ & $2(66.67)$ & $0(0)$ & $1(100)$ & $1(50)$ & $1(50)$ \\
\hline Amikacin & $79(97.53)$ & $2(2.47)$ & $0(0)$ & $3(100)$ & $0(0)$ & $1(100)$ & $0(0)$ & $2(100)$ \\
\hline Ofloxacin & $31(38.27)$ & $50(61.73)$ & $0(0)$ & $3(100)$ & $0(0)$ & $1(100)$ & $0(0)$ & $2(100)$ \\
\hline Cloxacillin & $41(50.62)$ & $40(49.38)$ & $3(100)$ & $0(0)$ & $0(0)$ & $1(100)$ & $2(100)$ & $0(0)$ \\
\hline Erythromycin & $12(14.81)$ & 69(85.19) & $3(100)$ & $0(0)$ & $0(0)$ & $1(100)$ & $2(100)$ & $0(0)$ \\
\hline Azithromycin & $49(60.49)$ & $32(39.51)$ & $3(100)$ & $0(0)$ & $1(100)$ & $0(0)$ & $2(100)$ & $0(0)$ \\
\hline Clindamycin & $47(58.02)$ & $34(41.98)$ & $2(66.67)$ & $1(33.33)$ & $1(100)$ & $0(0)$ & $1(50)$ & $1(50)$ \\
\hline Teicoplanin & $75(92.59)$ & $6(7.41)$ & $0(0)$ & $3(100)$ & $1(100)$ & $0(0)$ & $0(100)$ & $2(100)$ \\
\hline Doxycyclin & $68(83.95)$ & $13(16.05)$ & $1(33.33)$ & $2(66.67)$ & $1(100)$ & $0(0)$ & $1(50)$ & $1(50)$ \\
\hline Linezolid & $73(90.12)$ & $8(9.88)$ & $0(0)$ & $3(s 100)$ & $0(0)$ & $1(100)$ & $0(0)$ & $2(100)$ \\
\hline Ampicillin & $5(6.17)$ & $76(93.83)$ & $3(100)$ & $0(0)$ & $1(100)$ & $0(0)$ & $2(100)$ & $0(0)$ \\
\hline
\end{tabular}

Antibiotic susceptibility pattern of $S$. aureus, CoNS, Enterococcus spp and Streptococcus spp.

Among 119 isolates, 81 were S. aureus. Out of total
S. aureus isolates Methicillin sensitive Staphylococcus aureus were 38(46.91\%) and Methicillin Resistant Staphylococcus aureus were 43(53.09\%). (Figure: 4)

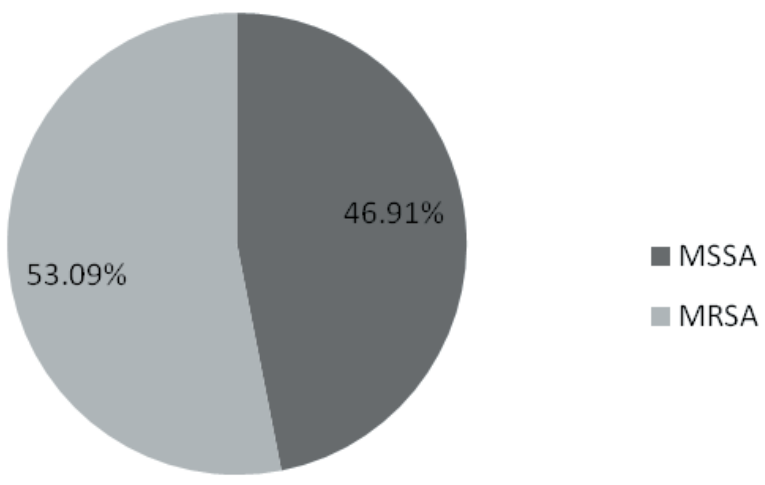

Figure 4: Distribution of MRSA among S. aureus 


\section{DISCUSSION}

In this study the overall rate of bacterial Soft tissues infection among the study population was found to be 199 (52.36\%). The result was in agreement with the study carried out by Sah et al. (2013) that reported 62\% growth rate and close to the result reported by Acharya et al. (2008), accounting 50.7\%. The predominance of male patients was seen in this study with male: female ratio of $65 / 35$ and this finding was similar to the other studies where a much higher number of male patients have been reported Sharma et al. (2013) and Gurung et al. (2018). The patients with age $>30$ years had a much higher incidence of STIs $(42.09 \%)$ in comparison to an incidence of $14.99 \%$ among the patients who were $\leq 29$ years of age. Similarly, the study carried out by Murphy et al. (2001) also had a much higher incidence of STIs $(89.41 \%)$ at age group $>30$ years. Advancing age is an important factor for the development of STIs, as in old age patients there is low healing rate, low immunity, increased catabolic processes and presence of co-morbid illness like diabetes, hypertension, etc. (Sharma et al. 2015).

In this study, the frequency of Gram-negative bacteria was higher than Gram positive bacteria. However, a similar study carried out by Surucuoglu et al. (2005) showed the higher prevalence of Gram-positive bacteria (69\%) than Gram negative bacteria (29\%). The higher prevalence of Gram-positive bacteria was also depicted in researches carried out by Kaftandzieva et al. (2012). Practically, S. aureus was the major pathogenic Gram positive organism and E. coli was the major pathogenic Gram negative organisms for STIs, as in the study carried out by Fazii et al. (2013), and Ranabhat et al. (2013) shows the most common bacterial species detected was Staphylococcus aureus $(37.50 \%)$ and E. coli $(25 \%)$. In the study carried out by Karkee (2008) reported similar results that the most common bacteria (46.58\%) were S. aureus, E. coli $(12.38 \%)$ emerged as the next common organism causing wound infection in this study as in the other previously reported studies which is followed by, CoNS $(11.40 \%)$ and $P$. aeruginosa $(7.49 \%)$. The least common bacteria isolated were C. freundii $(0.65 \%)$. In Saudi Arabia, Abussaud (1996) isolated S. aureus (35\%), P. aeruginosa (25\%) and Klebsiella spp (10\%) as the major causative agents.

However, different studies showed that $P$. aeruginosa was the leading cause of wound infections. In a study conducted by Mousa (1997) to assess the rate of wound infection by aerobic bacteria and found that $19.1 \%$ of the wound infection was caused by $P$. aeruginosa. Similar study on wound infection by Nasser et al. (2003) showed P. aeruginosa (21.6\%) as the most common isolate which in compare to our result was similar as the rate of infection by $P$. aeruginosa was fond to be $15.07 \%$.

In antibiotic susceptibility pattern of Gram negative organism, gentamycin was most sensitive (62.83\%) followed by amikacin (47.78\%), Levofloxacin (39.76\%), PTZ (38.05\%), Doxycycline (34.94\%), Cotrimoxazole (32.53\%), Ofloxacin (30.12\%), Ciprofloxacin (28.32\%), Piperacillin (22.12\%), Ceftriaxone (18.07\%), Cefotaxime (13.25\%), Ampicillin (12.05\%), Amoxyclav (12.04\%) and Amoxycillin (4.81\%). However, the study carried out by Timalsina et al. (2015) for Gram negative isolates, Amikacin $(45,93.75 \%)$ was found to be the most sensitive antibiotic followed by Gentamycin (42, 89.36\%), Ciprofloxacin (27, 56.25\%) while Amoxycillin $(13,32.5 \%)$ and Cotrimoxazole $(14,29.16 \%)$ being the least sensitive antibiotic respectively. In our study, among Gram positive isolates, the most effective antibiotic was Amikacin (91.86\%) followed by Teicoplanin $(88.37 \%)$, Linezolid $(84.88 \%)$, Doxycycline (82.56\%), Gentamycin (75.58\%), Azithromycin (63.95\%), Clindamycin (59.30\%), Cloxacillin (53,49\%), Cotrimoxazole (39.53\%), Ofloxacin (36.04\%), Erythromycin (19.77\%) and Ampicillin (12.79\%). However, Tuladhar (1999) reported that Gentamicin was found to be most effective (89.53\%) drug followed by Ciprofloxacin (83.72\%) while only $16.27 \%$ of Grampositive cocci were sensitive to Ampicillin.

The patterns of MDR among Gram negative bacterial isolates were $100 \%$ in Acinetobacter spp, $83.33 \%$ in Enterobacter spp, $77.77 \%$ in Klebsiella pneumoniae, 64.86\% in Escherichia coli, 50\% in Proteus mirabilis, 50\% in Citrobacter freundii, 50\% in Citrobacter koserii, 10\% in Pseudomonas spp and no any MDR isolates in Klebsiella oxytoca and Serratia marcescens which was in contrast to results shown by Bhandari (2014) that reported that higher number of $E$. coli isolates, 64 (72.7\%) were multi drug resistant followed by Pseudomonas aeruginosa 11 (91.7\%) and K. pneumoniae 6 (75\%). Out of all GPC, $81(94.17 \%)$ were S. aureus in which $43(53.06 \%)$ were MRSA and 38(46.94\%) were MSSA which was similar to the study performed by Khanal and Jha (2010) which showed $68 \%$ MRSA and 32\% MSSA. The study performed by Edelsberg et al. (2009) also showed 35.9\% 
MRSA which is also contrast to our study. Though a great array of bacteria is involved in wound infections, we were able to trace limited pathogens due to lack of adequate laboratory facilities and time boundary.

\section{CONCLUSION}

The rate of wound infection is higher among the patients visiting the tertiary care hospital in Kathmandu. The antibiotic susceptibility pattern of the pathogens causing wound infections in the study population revealed higher rate of multidrug resistant, indicating the limited therapeutic alternatives for the management of wound infected patients.

\section{ACKNOWLEDGEMENTS}

We are most grateful to Head of Department of Microbiology of Birendra Military Hospital for providing us clinical facilities and the necessary support. We would also like to thank all the staffs of Sainik Awasiya Mahavidyalaya for their continuous support and suggestions.

\section{CONFLICT OF INTEREST}

The author declares no conflict of interest.

\section{REFERENCES}

Baddour ML (2019). Patient's education on skin and soft tissue infection (cellulitis). Available at https:// www.uptodate.com/contents/skin-and-softtissue-infection-cellulitis-beyond-the-basics\#!

Rosser WW, Pennie RA and Pila NJ (2005). The AntiInfective Review Panel. Anti-Infective Guidelines for Community-Acquired Infections Toronto: MUMS Guideline Clearinghouse.

Woerther PL, Burdet C, Chachaty E and Andremont A (2013). Trends in human fecal carriage of extended-spectrum $\beta$-lactamases in the community toward the globalization of CTX-M: Clin Microbiol Rev 26: 744-758.

Barrett PF, McGehee RF and Finland M (1968). Methicillin Resistant Staphylococcus aureus at Batten city Hospital: Bacteriological and epidemiological observations. New Engl J Med 279: 441-448.

Ciccarone D, Bamberger J and Kral A (2001). Soft tissue infections among injection drug users- San Fransisco, California, 1996-2000. J Amer Med Assoc 285: 2707-2709.

Hersh AL, Chambers HF, Maselli JH and Gonzales R
(2008). National trends in Ambulatory visits and Antibiotic Prescribing for skin and soft-tissue infections: Arch Intern Med 168: 1585-1591.

Edelsberg J, Taneja C, Zervos M, Haque N, Moore C, Reyes K, Spalding J, Jiang J and Oster G (2009). Trends in US hospital admissions for skin and soft tissue infections: Emerg Infect Dis 15: 1516-1518.

WHO (2003). The World Health Report. Geneva, Switzerland.

Cheesbrough M (2006). District laboratory practice in tropical countries 2 .

CLSI (2014). Performance standards for antimicrobial susceptibility testing; twenty-second Informational supplement 33. CLSI Document M100-S20. Wayne, PA.

Magiorakos AP, Srinivasan A, Carey RB, Carmeli Y, Falagas ME, Giske CG, Harbarth S, Hindler JF, Kahlmeter G, Olsson-Liljequist B, Paterson DL, Rice LB, Stelling J, Struelens MJ, Vatopoulos A, Weber JT and Monnet DL (2012). Multidrug resistant, extensively drug-resistant and pandrug-resistant bacteria: an international expert proposal for interim standard definitions for acquired resistance. Clin Microbiol Infect 18: 268-281.

Sah P, Khanal R and Upadhaya S (2013). Skin and soft tissue infections: Bacteriological profile and antibiotic resistance pattern of isolates. J Universal College Medical Science 3: 18-21.

Acharya J, Mishra SK, Kattel HP, Rijal B and Pokharel BM, (2008). Bacteriology of wound infections among patients attending Tribhuwan University Teaching Hospital, Kathmandu, Nepal: Journal of Nepal Association for Medical Laboratory Sciences 9: 76-80.

Murphy EL, Vita DD, Liu H, Vittinghoff E, Leung P, Ciccarone DH and Edlin BR (2001). Risk Factors for Skin and Soft-Tissue Abscesses among Injection Drug Users: A Case-Control Study. Clin Infect Dis 33: 35-40.

Kaftandzieva A, Cekovska Z, Kaftandzieva I, Panovski N and Petrovska M (2012). Bacteriology of wound-clinical utility of gram stain microscopy and the correlation with culture. Macedonian 
Journal of Medical Sciences 5: 72-77.

Bessa LJ, Fazii P, Giulio DM and Cellini L (2013). Bacterial isolates from infected wounds and their antibiotic susceptibility pattern: some remarks about wound infection: The International Wound Journal 12: 47-52.

Surucuoglu S, Gazi H, Kurutepe S, Ozkutuk N and Ozbakkaloglu B (2005). Bacteriology of surgical wound infections in a tertiary care hospital in Turkey. East Afr Med J 82: 331-336.

Karkee P (2008). Bacterial Isolates and their Antibiogram from Wounds and Abscesses of Surgical Outpatients Visiting Bir Hospital: M. Sc. Dissertation Submitted to the Department of Microbiology, Tribhuvan University: 13-29.

KC R, Shrestha A and Sharma V (2014). Bacteriological study of wound infection and antibiotic susceptibility pattern of the isolates. Nepal Journal of Science and Technology 14: 143-150.

Abbussaud MJ (1996). Incidence of wound infection in three different departments and the antibiotic sensitivity pattern of the isolates in a Saudi Arabian hospital: Acta Microbiol Immunol Hunga 43: 301-305.

Mousa HA (1997). Aerobic, anaerobic and fungal burn wound infections: J Hosp Infect 37: 317-323.

Tuladhar P (1999). A prospective study on bacteriology of wound infection at TUTH: A dissertation presented to the Central Department of Microbiology, Tribhuvan University, Kathmandu, Nepal.

Khanal LK and Jha BK (2010). Prevalence of methicillin resistant Staphylococcus aureus (MRSA) among skin infection cases at hospital in Chitwan, Nepal: Nepal Med Coll J 12: 224-228.

Edelsberg J, Taneja C, Zervos M, Haque N, Moore C, Reyes K, Spalding J, Jiang J and Oster G (2009). Trends in US hospital admissions for skin and soft tissue infections: Emerg Infect Dis 15: 1516-1518. 